\title{
Green synthesis of silver nanoparticles using Zygophyllum qatarense Hadidi leaf extract and evaluation of their antifungal activities
}

\author{
R. Barzegar ${ }^{1}$, H. R. Safaei ${ }^{1}$, Z. Nemati $^{1}$, S. Ketabchi $^{2}$, E. Talebi $^{3}$ \\ ${ }^{1}$ Department of Applied Chemistry, Shiraz branch, Islamic Azad University, Shiraz, Iran. \\ ${ }^{2}$ Department of Plant Pathology, Shiraz branch, Islamic Azad University, Shiraz, Iran. \\ ${ }^{3}$ Darab branch, Islamic Azad University, Darab, Fars, Iran.
}

\begin{tabular}{l} 
ARTICLE INFO \\
\hline Article history: \\
Received on: $24 / 02 / 2017$ \\
Accepted on: $12 / 06 / 2017$ \\
Available online: $30 / 03 / 2018$ \\
\hline Key words: \\
Zygophyllum qatarense \\
Hadidi, Silver Nanoparticles, \\
Antifungal Activity.
\end{tabular}

\section{ARTICLE INFO}

Accepted on: 12/06/2017

Key words:

Hadidi, Silver Nanoparticles,

Antifungal Activity.

\begin{abstract}
In this study, silver nanoparticles were biosynthesized from the methanolic extract of Zygophyllum qatarense Hadidi leaf extract. The methanolic extract of Zygophyllum qatarense Hadidi leaf was used as a stabilizer and reducing agent to reduce $\mathrm{Ag}^{+}$to metallic silver. The produced silver nanoparticles have the average size of 47 $\mathrm{nm}$ as confirmed with UV-visible spectroscopy and scanning electron microscope. Furthermore, the antifungal activity of synthesized nanoparticles, methanolic extract of Zygophyllum qatarense Hadidi leaf, and silver nitrate were investigated against Aspergillus nigera and Penicillium digitatum by disk diffusion and micro broth dilution methods. All of the treatments showed antifungal activity, but silver nanoparticles when compared with other treatments had a significant effect against the Aspergillus niger and Penicillium digitatum.
\end{abstract}

\section{INTRODUCTION}

Silver nanoparticles have been widely used for various purposes, such as medical devices, cleaning agents etc., due to its unique antimicrobial properties. Generally, the method for the silver nanoparticles preparation involves the reduction of silver ions in the solution. However, the reducing reagents, such as sodium borohydride, may increase the environmental toxicity or biological hazards. Hence, the development of a green synthesis of silver nanoparticles using environment-friendly solvents and nontoxic reagents is of great interest. Sun et al. described the silver nanoparticles synthesis using a leaf extract of Cinnamomum camphora, while the reduction was considered due to the phenolics, terpenoids, polysaccharides and flavonoids

\footnotetext{
* Corresponding Author

Email: barzegar.phytochemist @ gmail.com

Phone: +989178954979
}

and flavonoids (Sun et al., 2014). Zygophyllum qatarense Hadidi is reported to contains alkaloids, sterols, and coumarins (Cybulska et al., 2014). The plant possess anti-inflammatory properties and also used to treats intestinal pains (Mahasneh et al., 2002). High antimicrobial activity was observed in butanol and ethanol extracts from Zygophyllum qatarense Hadidi against pathogens such as Staphylococcus aureus, Escherichia coli, Pseudomonas aeruginosa, and Candida albicans (Cybulska et al., 2014). Also, fresh organ leaves powder and twigs from Zygophyllum qatarense Hadidi were used for wound healing and earache (Safa et al., 2013). All the above properties makes this plant a suitable candidate for this study.

In this study, the methanolic extract of Zygophyllum qatarense Hadidi leaf and silver nitrate solution were used for synthesis of silver nanoparticles. Further, the antifungal activity of silver nanoparticles, methanolic extract of Zygophyllum qatarense Hadidi leaf, and silver nitrate were evaluated by standard disk diffusion, the minimum inhibitory concentration (MIC), and the minimum fungicidal concentration (MFC) methods. 


\section{MATERIALS AND METHODS}

Zygophyllum qatarense Hadidi leaf was collected from Bandar Abas, Iran. The plant material was thoroughly washed and dried in shade.

The formation of silver nanoparticles in size of 400 to $500 \mathrm{~nm}$ was determined using UV-Vis spectroscopy device (model DR 5000-HACH) and also the scanning electron microscope (SEM) device (KYKYDIGITAL-EM3200) is used to specify size and shape of silver nanoparticles. The Aspergillus niger and Penicillium digitatum was procured from Shiraz branch, Islamic Azad University. In this study methanol, DMSO, potato dextrose agar (PDA) and potato dextrose broth (PDB) medium were procured from Merck \& Co, USA, whereas the silver nitrate was procured form Sigma-Aldrich, USA.

\section{The extraction of Zygophyllum qatarense Hadidi leaf}

The $10 \mathrm{~g}$ of dried Zygophyllum qatarense Hadidi leaves were mixed with $100 \mathrm{ml}$ of methanol (95\%) and refluxed for 30 min. The extract was filtered through whatman (no. 1) filter paper.

\section{Synthesis of Silver Nanoparticles}

The methanolic extract of Zygophyllum qatarense Hadidi leaf and silver nitrate solution $(0.1 \mathrm{M})$ were mixed together in different ratios. These mixtures were heated at $70{ }^{\circ} \mathrm{C}$ until reduced by half and then the synthesized nanoparticles were separated.

\section{Antifungal activity}

The synthesized nanoparticles, Zygophyllum qatarense Hadidi leaf extracts, silver nitrate and Cotrimoxazol were dissolved in DMSO and the final concentration were made to 512, 256, 128, $64 \mu \mathrm{g} / \mathrm{ml}$ concentrations. The plates contain four concentration of treatments were incubated for 48 to 72 hours at $29^{\circ} \mathrm{C}$. Finally, the inhibition zone was measured in millimeter.

\section{The minimum inhibition concentration (MIC)}

The $95 \mu$ l of potato dextrose broth (PDB) was placed into the cells of micro plate and $100 \mu \mathrm{l}$ of each sample was added to the first cell of each row. After mixing the contents of the first cells, $100 \mu \mathrm{l}$ was removed and added to the next cell and so till ninth cells of every row. Finally, the $5 \mu$ l of fungal suspension was added to all cells of micro plate except tenth cells. The tenth cells of each rows was served as a control.

\section{The minimum fungicidal concentration (MFC)}

MFC was determined on cultured fungal cells in potato dextrose agar (PDA) medium and incubated for 48 to 72 hours at $29{ }^{\circ} \mathrm{C}$. The lowest concentration of treatments that inhibited 99.9 $\%$ of fungal cell growth was considered as minimum fungicidal concentration (MFC) (Ahmadi et al., 2015).

\section{RESULTS AND DISCUSSION}

In this experiment, methanol extract of Zygophyllum Qatarense Hadidi leaf and silver nitrate solution were mixed with each other in different ratios. The changing solution color from dark green to brown was considered as progress of this reaction (Fig. 1).

\section{UV-Vis Analysis}

UV-visible spectrum showed only 1 to 1 ratio of methanol extract of Zygophyllum Qatarense Hadidi leaf and silver nitrate solution, the maximum absorbance peak was $454 \mathrm{~nm}$. (Fig.1). The methanolic extract of Zygophyllum Qatarense Hadidi leaf was used as a stabilizer and reducing agent to reduce Ag+ to metallic silver because Zygophyllum Qatarense Hadidi leaf contain some phytochemical compounds that can be reducing Ag+ to $\mathrm{Ag}^{0}$.

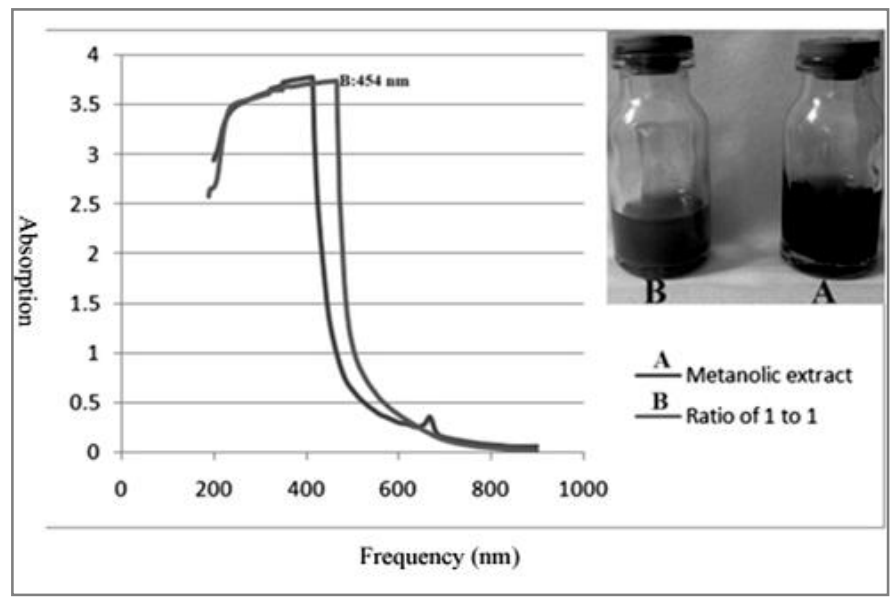

Fig 1: Schematic of UV-Vis spectra before (A) and after reaction (B).

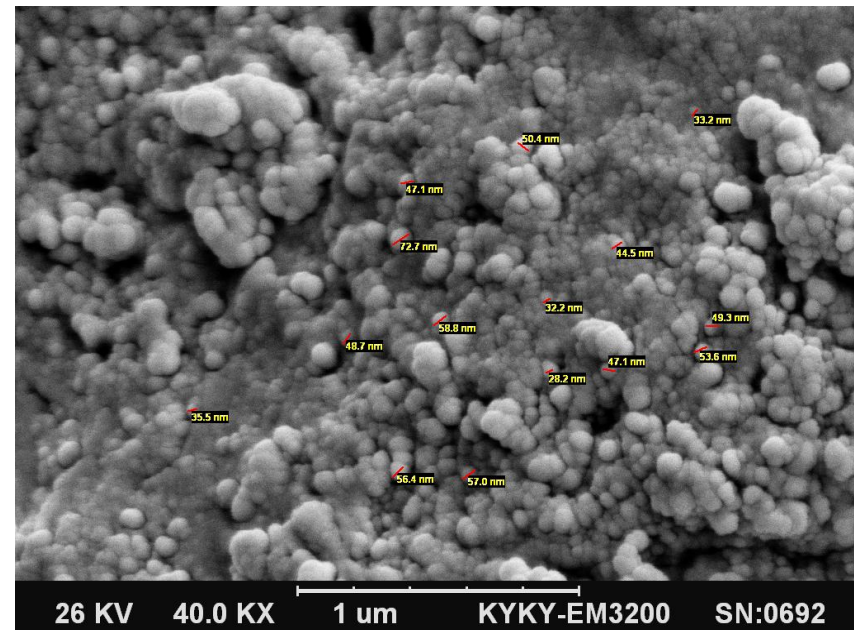

Fig. 2: Scanned image of silver nanoparticles synthesized by using the Scanning electron microscope (SEM). 

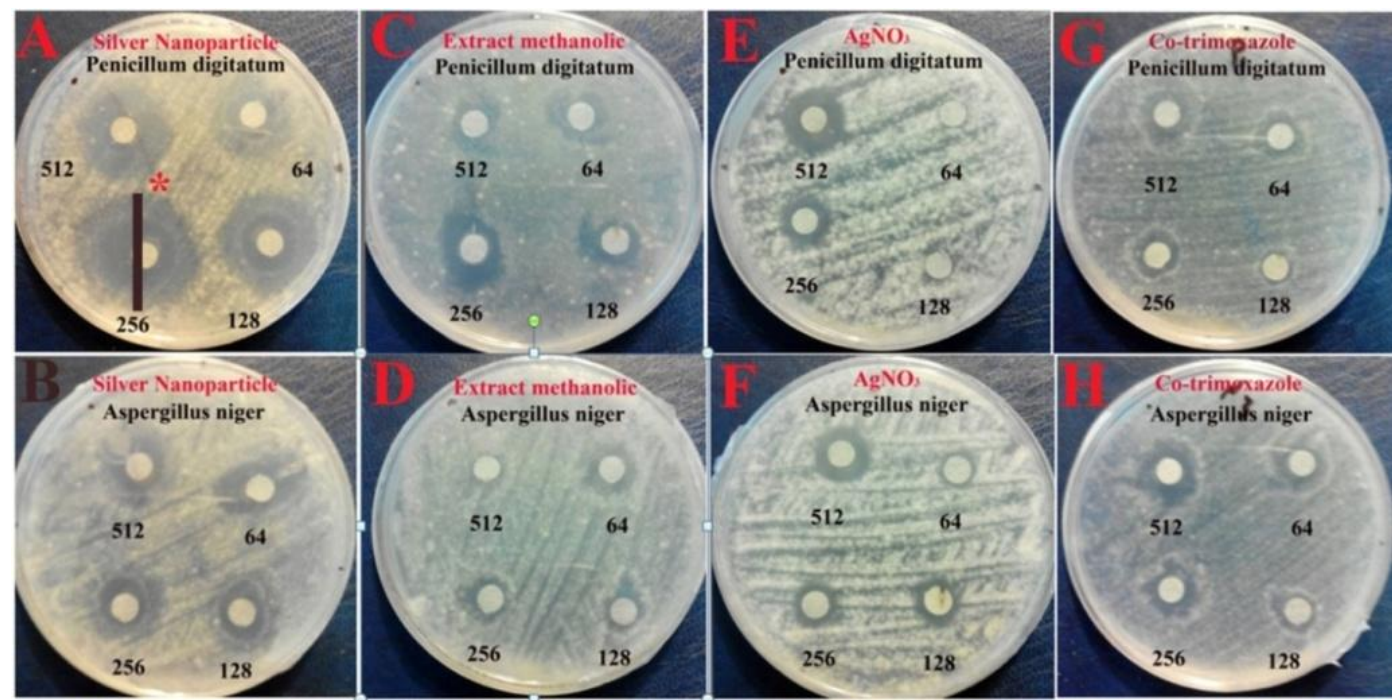

Fig. 3: Antifungal activity of treatments in 512,256, 128 and $64 \mu \mathrm{g} / \mathrm{ml}$ concentrations against Aspergillusnige and Penicillum digitatum (*Inhibition zone in millimeter).

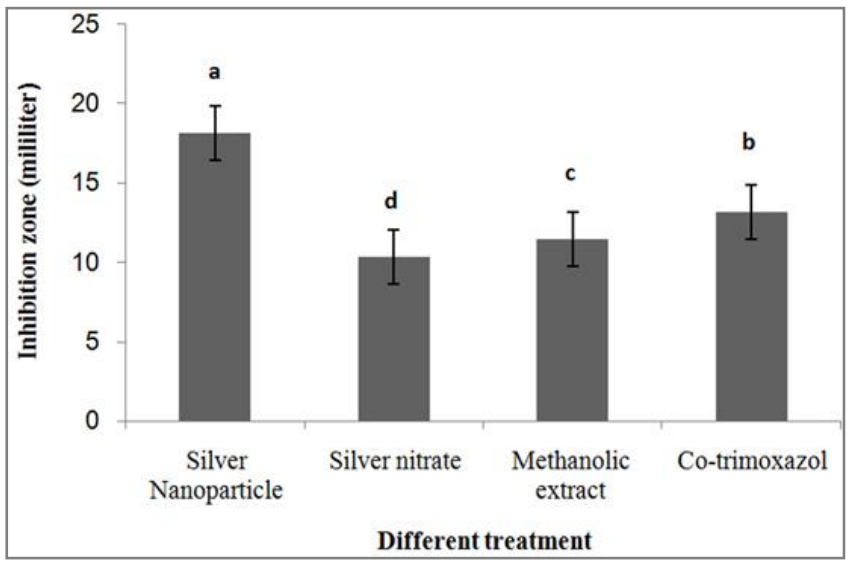

Fig. 4: Comparison of antifungal activity of different treatments against Penicillium digitatum and Aspergillus niger.

Table 1: The inhibition zone size of disks contain treatments against Penicillum digitatum and Aspergillus niger in millimeter and the results of $\mathrm{MIC}$ and MFC in $\mu \mathrm{g} / \mathrm{ml}$.Silver nitrate and Co-trimoxazol were as a control.

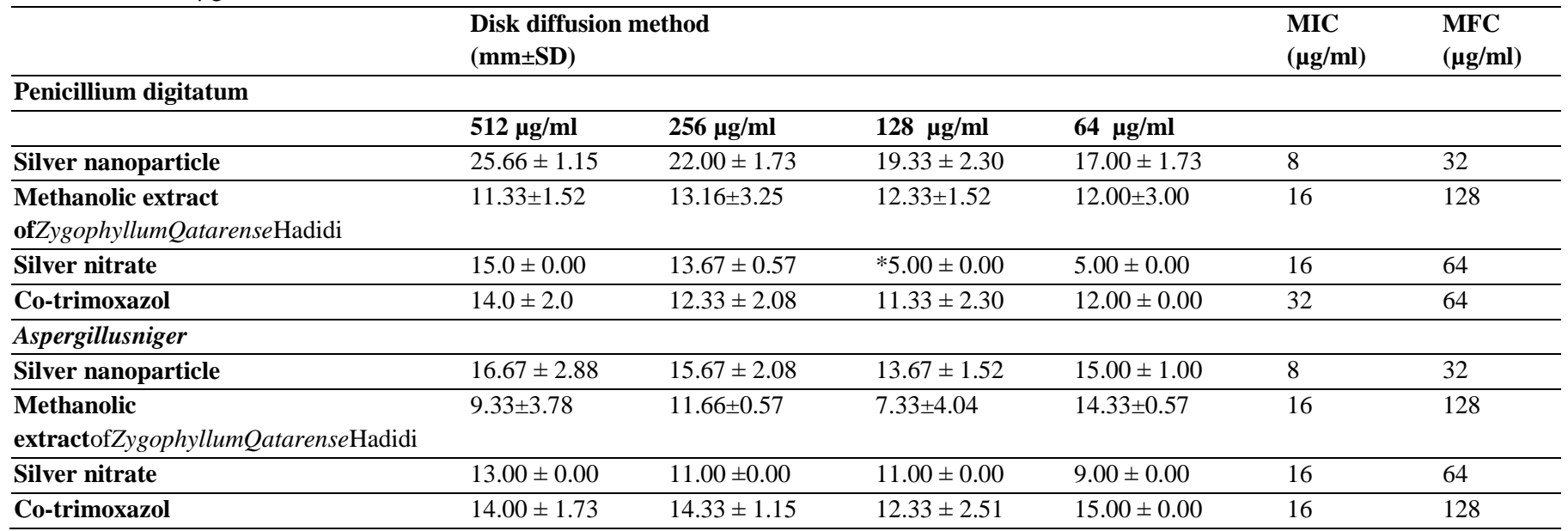

*Inhibition zone in millimeter and the size of disks was $5 \mathrm{~mm}$. 


\section{SEM Analysis}

The shape and average size of silver nanoparticles have been found $47 \mathrm{~nm}$ by scanning electron microscope (SEM) (Fig. 2).

\section{The antifungal activity by disk diffusion method}

The results showed inhibition zone of silver nanoparticles in the concentrations of $512,256,128$ and $64 \mu \mathrm{g} / \mathrm{ml}$ for Penicillium digitatum respectively was $25.66 \pm 1.15 \mathrm{~mm}, 22.00$ $\pm 1.73 \mathrm{~mm}, 19.33 \pm 2.30 \mathrm{~mm}$ and $17.00 \pm 1.73 \mathrm{~mm}$. Whereas for Aspergillus niger the diameter of inhibition zone was $16.67 \pm 2.88$ $\mathrm{mm}, 15.67 \pm 2.08 \mathrm{~mm}, 13.67 \pm 1.52 \mathrm{~mm}$ and $15.00 \pm 1.00 \mathrm{~mm}$. The inhibition zone of methanol extract against Penicillium digitatum in the concentrations of $512,256,128$ and $64 \mu \mathrm{g} / \mathrm{ml}$ was $11.33 \pm 1.52 \mathrm{~mm}, 13.16 \pm 3.25 \mathrm{~mm}, 12.33 \pm 1.52 \mathrm{~mm}$ and $12.00 \pm 3.00$ $\mathrm{mm}$ respectively and against Aspergillus niger was 9.33 \pm 3.78 , $11.66 \pm 0.57,7.33 \pm 4.04$ and $14.33 \pm 0.57 \mathrm{~mm}$. Co-trimoxazol and Silver nitrate were as a control (Fig.4) (Table 1).

\section{Determination of MIC and MFC}

The results showed the minimum inhibitory concentration (MIC) of silver nanoparticles against Penicillium digitatum and Aspergillus niger was $8 \mu \mathrm{g} / \mathrm{ml}$ and for methanolic extract of Zygophyllum qatarense Hadidi leaf was $16 \mu \mathrm{g} / \mathrm{ml}$. Also the minimum fungicidal concentration (MFC) of silver nanoparticles against Penicillium digitatum and Aspergillus niger was $32 \mu \mathrm{g} / \mathrm{ml}$ and for methanolic extract of Zygophyllum qatarense Hadidi was $128 \mu \mathrm{g} / \mathrm{ml}$. Co-trimoxazol and silver nitrate were served as a control. Silver nanoparticles had more effects in compared with other treatments in the MIC and MFC methods (Table 1).

\section{CONCLUSIONS}

Our results were showed methanolic extract of Zygophyllum qatarense Hadidi leaf can be used for synthesis silver nanoparticles as an efficient green reagent without needing to chemical compounds. The synthesis method is very easy and cheap. The silver nanoparticles and methanolic extract of Zygophyllum qatarense Hadidi leaf has unique biological properties and can be used in Pharmaceutical industries.
Financial support and sponsorship: Nil

Conflict of interests : There are no conflicts of interest.

\section{ACKNOWLEDGMENT}

The authors would like to thank Research Center of Islamic Azad University Shiraz Branch for partial supporting of this research.

\section{REFERENCES}

Sun Q, Cai X, Li J, Zhengb M, Chenb Z, Yua CP. Green synthesis of silver nanoparticles usingtea lea $f$ extract and evaluation of their stability and antibacterial activity. Colloids and SurfacesA: Physicochemical and Engineering Aspects, 2014; 444: 226- 231.

Cybulska I, Brudecki G, Alassali A, Thomsen M and Brown J.J. Phytochemical composition of some common coastal halophytes of the United,Emirates journal of food and agriculture; 2014. 26 (12): 1046-1056

Mahasneh AM. Screening of Some Indigenous Qatari Medicinal Plants for AntimicrobialActivity; Phytotherapy research. 2002; 16: 751753.

Safa O, Soltanipoor MA, Rastegar A, Kazemi M, Dehkordi KN, Ghannadi A. Anethnobotanical survey on hormozgan province, Iran; Avicenna Journal of Phytomedicine; 2013;3(1): 64-81.

Anitha R, Karthikeyan B, Pandiyarajan T, Vignesh S, Arthur James R, Vishwanathan K, MurariBM. Antifungal Studies on Biocompatible Polymer Encapsulated Silver Nanoparticles; International Journal of Nanoscience, 2011; 10(4): 1179-118.

Ahmadi R, Alizadeh A, Ketabchi S. Antimicrobial activity of the essential oil of Thymus kotschyanus grown wild in Iran; International Journal of Biosciences, 2015, 6(30): 239-248

\section{How to cite this article:}

Barzegar R, Safaei HR, Nemati Z, Ketabchi S, Talebi E. Green synthesis of silver nanoparticles using Zygophyllum qatarense Hadidi leaf extract and evaluation of their antifungal activities. J App Pharm Sci, 2018; 8 (03): 168-171. 